\title{
REVISTA CONTABILIDADE \& FINANÇAS - USP: UMA COMPARAÇÃO ENTRE OS PERÍODOS 1989/2001 E 2001/2004
}

\author{
ALEXANDRE CÉSAR BATISTA DA SILVA \\ Mestrando pelo Mestrado Multiinstitucional e Inter-Regional das Universidades \\ UnB, UFPB, UFPE e UFRN \\ E-mail: acbspe@uol.com.br
}

\section{ELYROUSE CAVALCANTE DE OLIVEIRA}

Mestranda pelo Mestrado Multiinstitucional e Inter-Regional das Universidades

UnB, UFPB, UFPE e UFRN

E-mail: rouse_cavalcante2@hotmail.com

\section{JOSÉ FRANCISCO RIBEIRO FILHO}

Prof. Dr. do Depto. de Ciências Contábeis da Universidade Federal de Pernambuco - PE

E-mail: francisco.ribeiro@ufpe.br

\section{RESUMO}

O objetivo deste trabalho é destacar a importância da Revista Contabilidade \& Finanças - USP no meio acadêmico nacional e observar as transformações ocorridas no periódico desde a pesquisa realizada por Martins (2002). A metodologia utilizada para tal foi o método dedutivo-analítico, descritivo, com abordagem qualitativa-quantitativa. Conclui-se que a Revista sofreu consideráveis mudanças no período 2001/2004, em que os resultados alcançados demonstram que houve uma evolução significativa principalmente com relação ao tipo de pesquisa utilizada para elaboração dos artigos, que era expressivamente bibliográfica e passou a ser em grande parte fruto de trabalhos empírico-teóricos. Outro aspecto relevante é o aumento na diversidade de autores e instituições que têm trabalhos publicados, antes grande maioria dos escritores eram de São Paulo e faziam parte ou tinham ligação com o Departamento de Contabilidade e Atuária da FEA - USP e no período em análise há participações dos vários Estados brasileiros e também de outros países.

Palavras-chave: Periódico; Evolução; Pesquisa; Conhecimento; Divulgação.

\section{ABSTRACT}

This article aims to highlight the importance of the Journal of Accounting \& Finance - USP in the Brazilian academic area and point out the changes this publication has gone through since the study by Martins (2002). We used a deductive-analytical and descriptive method from a quali-quantitative approach. Considerable changes were made between 2001 and 2004, resulting in a meaningful evolution in terms of research types used to elaborate the articles, which were mostly empiric-theoretical. Another essential fact is the increased diversity of authors and institutions represented in the Journal, proceeding not only from different Brazilian states but also from other countries.

Keywords: Journal; Evolution; Research; Knowledge; Release. 


\section{CONSIDERAÇÕES INICIAIS}

Segundo Marconi e Lakatos (2001), o conhecimento científico visa explicar "porque" e "como" os fenômenos ocorrem, na tentativa de evidenciar os fatos que estão correlacionados, numa visão mais globalizante. Essa é uma percepção que se torna clara ao analisar-se a evolução do saber científico e ao observar-se que é decorrente de um agregado de estudos, descobertas, análises etc. que vão se acumulando através do tempo e que formam um arcabouço conceitual sobre cada um dos vários conhecimentos classificados como Ciência. Este trabalho se relaciona com essa evolução do conhecimento científico ao comparar as publicações no período 2001/2004 com os trabalhos apresentados no período 1989/2001, de acordo com a pesquisa realizada por Martins (2002) sobre os doze anos de publicação do Caderno de Estudos da USP, atual Revista Contabilidade \& Finanças - USP.

Bachefard apud Silva (2003) diz que a Ciência não corresponde a um mundo a descrever, corresponde a um mundo a construir. Essa construção é caracterizada como fruto do trabalho desenvolvido por estudiosos, pesquisadores, professores, alunos, ou seja, por todo um conjunto de pessoas que têm como interesse comum tentar explicar os fenômenos que acontecem ao seu redor e que estão compreendidos dentro dos seus objetos de estudo. Então, os resultados dessa pesquisa poderão ser úteis a todos os que têm interesse nos trabalhos científicos desenvolvidos na área de Contabilidade e Finanças, aos autores que divulgam seus trabaIhos no periódico e também aos que produzem a Revista, que têm atualmente o reconhecimento do seu trabalho ratificado pelo sistema QUALIS (Sistema de classificação de periódicos, anais e revistas) da CAPES ao considerar a Revista como "A" Nacional.

Grande parte da produção científica evidenciada, hoje, no Brasil é fruto de trabalhos realizados nos cursos de pós-graduação lato sensu e stricto sensu promovidos pelas instituições de ensino superior. São estudos que buscam evidenciar os vários temas correlatos ao conhecimento, destacando-se, sobretudo, os temas emergentes. Em Contabilidade, assim como em outras Ciências, os trabalhos realizados nos cursos de pósgraduação representam uma parcela considerável do conhecimento produzido sobre a Ciência. Segundo Oliveira (2002), os artigos publicados em periódicos representam uma relevante parte do fluxo de informação originado com a atividade científica da pesquisa. São trabalhos que obedecem a rigores científicos e assim sendo são di- vulgados em periódicos, congressos, eventos etc. que buscam evidenciar estudos de qualidade e que versem sobre temas que sejam úteis a toda classe interessada.

De acordo com Schwartzman (1984, p. 25-32):

Publicações científicas e técnicas, quando feitas em revistas de boa qualidade, dotadas de sistemas adequados de avaliação e crítica de manuscritos, desempenham ainda duas funções primordiais, ainda que pouco evidentes à primeira vista. Primeiro, elas têm um importante papel pedagógico junto ao pesquisador, que é levado a expor o resultado de sua pesquisa a outros especialistas em seu campo, recebendo sugestões, críticas e comentários que podem ser decisivos para aperfeiçoar e mesmo reorientar os trabalhos. Segundo, os corpos editoriais das revistas funcionam como um mecanismo altamente qualificado de avaliação final da pesquisa.

Observa-se a importância da produção científica decorrente dos cursos de pós-graduação na área das Ciências Contábeis e também tem inestimável valor a divulgação desses estudos através de periódicos, pois esse conjunto faz com que as bases do conhecimento sejam solidificadas e sirvam de suporte para que haja uma possibilidade cada vez maior de avanço no desenvolvimento científico.

\subsection{Objetivos do Estudo}

Este trabalho tem como objetivo geral analisar o desenvolvimento do periódico Contabilidade \& Finanças - USP como relevante ferramenta de divulgação do conhecimento científico em Contabilidade. Como objetivos específicos, procura fazer uma análise comparativa dos trabalhos publicados nos períodos 1989/2001 e 2001/2004, tendo como parâmetro as pesquisas feitas por Martins (2002) sobre o período 1989/2001, procura também identificar as mudanças ocorridas nos artigos publicados na revista desde então. E, ainda, busca, através de dados estatísticos, evidenciar as características intrínsecas dos artigos e dos autores no período 2001/2004.

\subsection{Metodologia do Estudo}

A pesquisa será conduzida de acordo com a metodologia proposta por Beuren (2003): quanto ao procedimento será dedutivo-analítica, quanto aos objetivos será descritiva e quanto à abordagem será qualitativa-quantitativa. 


\section{REVISÃO DA LITERATURA}

\subsection{A Pesquisa Científica em Contabilidade e os Cursos de Pós-Graduação Lato Sensu e Stricto Sensu}

A pesquisa científica em Contabilidade vem sendo fortalecida dia-a-dia com o empenho de pesquisadores, professores, estudantes etc. que buscam analisar os fenômenos que ocorrem no âmbito da Ciência Contábil. Esta pesquisa tem grande parte da sua origem na produção decorrente dos cursos de pós-graduação Lato Sensu e Stricto Sensu.

De acordo com Silva et al. (2004), os cursos de pós-graduação Lato Sensu, em geral, exigem ao seu término a elaboração de um artigo ou monografia. Os cursos de mestrado e doutorado exigem apresentação de dissertação, ensaio ou defesa de tese. Todo esse material produzido acrescenta à Contabilidade uma exposição em caráter de pesquisa científica sobre temas diversos, aumentando, assim, a divulgação do conhecimento e difundindo a Ciência Contábil como ramo do conhecimento que busca prover seus usuários de informações úteis, tempestivas e auxiliares do processo decisório, em qualquer esfera empresarial em que ele se faça necessário.

Segundo Oliveira (2002), essa produção é mais bem contextualizada nas regiões onde estão concentrados os cursos de pós-graduação em Contabilidade, visto que um dos focos principais desses cursos é a preparação dos alunos para o exercício da docência e para a realização de pesquisas científicas. Ainda segundo a autora, os conteúdos abordados nos artigos são de grande interesse para a comunidade contábil e também tratam de temas escassos na literatura nacional, destacando, desse modo, a importância das pesquisas. Este fato contextualiza-se na Revista Contabilidade \& Finanças - USP ao observar-se a grande quantidade de trabalhos publicados pelos alunos dos cursos de Mestrado e Doutorado em Contabilidade da USP.

As pesquisas da área contábil em sua maioria são apresentadas em encontros, congressos e sobretudo publicadas em periódicos, viabilizando a difusão do conhecimento.

\subsection{Breves Comentários sobre os Periódicos Nacionais de Divulgação da Pesquisa Científica}

Como principais instrumentos de divulgação do trabalho científico brasileiro, há uma preocupação quanto a qualidade dos periódicos que di- vulgam esses trabalhos. Segundo Krzyzanowski e Ferreira (1998), tem-se uma preocupação quanto à publicação de revistas sem critérios de qualidade e com as quais vêm se perdendo esforços, material publicado, recursos financeiros e até prestígio de organizações científicas ou instituições.

Conforme a pesquisa realizada por Oliveira (2002), relatando uma análise feita sobre os periódicos brasileiros de Contabilidade, destacam-se alguns aspectos importantes: 1 . a maioria dos autores são docentes, o que evidencia que grande parte das pesquisas em Contabilidade são originárias das universidades; 2. muitos autores são pós-graduados, caracterizando a importância dos periódicos como meio de divulgação para a comunidade científica nacional; 3. os temas mais privilegiados com trabalhos são Contabilidade Gerencial, Contabilidade Financeira, Teoria da Contabilidade, Educação e Pesquisa Contábil e Contabilidade de Custos, fato que demonstra a importância da Contabilidade Gerencial e das pesquisas sobre esse tema.

Porém, há uma preocupação com relação aos periódicos e aos trabalhos neles divulgados quanto à qualidade, visto que é através dessas publicações que a produção do conhecimento científico brasileiro é externada nacional e internacionalmente.

Neto et al. (2003), em pesquisa realizada sobre as publicações científicas em Contabilidade no período de 1990 a 2003, destacam que a produção nacional na área contábil tem baixo percentual em relação à produção internacional. É uma produção acanhada relativa às necessidades da comunidade acadêmica e até mesmo aos anseios da sociedade.

Verifica-se, então, que, apesar do avanço observado em alguns periódicos, ainda há grande carência com relação à quantidade de trabalhos produzidos e também preocupação relativa à qualidade dos artigos apresentados, onde se constata a necessidade de buscar-se um avanço nas pesquisas e temas tratados e também na própria estrutura das revistas, para que essas possam ter não apenas uma maior inserção nacional, mas também internacional. Dessa forma, a produção científica brasileira, também, terá repercussão em centros acadêmicos de outros países.

\section{O CADERNO DE ESTUDOS, ATUAL REVISTA CONTABILIDADE \& FINANÇAS - USP: ANÁLISE COMPARATIVA ENTRE OS PERÍODOS 1989/2001 (10 QUADRIMESTRE) E 2001/2004}

A Revista Contabilidade \& Finanças - USP teve seu primeiro fascículo publicado em 1989 e, na épo- 
ca, era denominada Caderno de Estudos. O Caderno teve, como órgão financiador, o IPECAFI - Instituto de Pesquisas Contábeis, Atuariais e Financeiras. De acordo com Martins (2002), na segunda capa do primeiro fascículo, em 1989, constava que:

O caderno de estudos é destinado à divulgação de pesquisas, reflexões, estudos, resumos de teses e demais produtos técnicos desenvolvidos por professores, pesquisadores, e alunos (principalmente Mestrado e Doutorado) do Departamento de Contabilidade da FEA/ USP também aberto para divulgação de materiais dos demais estudiosos desse campo.

Os primeiros fascículos apresentavam trabaIhos quase que exclusivamente de professores e alunos da própria USP, eram editados em formato de brochura e limitados quanto aos aspectos formais. A partir de 2001, o periódico teve seu nome alterado para Revista Contabilidade \& Finanças - USP e, a partir daí, verifica-se considerável meIhoria na apresentação e na qualidade dos trabalhos divulgados.

Atualmente, a Revista tem edição quadrimestral, é publicada pelo Departamento de Contabilidade e Atuária da FEA/USP, sua distribuição é gratuita e tem apoio financeiro da FIPECAFI (Fundação Instituto de Pesquisas Contábeis, Atuariais e Financeiras). O objetivo do periódico é divulgar artigos/ trabalhos de professores, pesquisadores e alunos (de pós-graduação e graduação) de todo o país e do exterior. Tem como missão a divulgação de produção científica relevante na área de Contabilidade, Controladoria, Atuária e Finanças, produzida por professores, pesquisadores, alunos e profissionais do Brasil e do exterior, selecionada exclusivamente com base em qualidade e efetiva contribuição para o desenvolvimento do conhecimento nesse campo. O periódico é considerado pela Coordenação de Aperfeiçoamento de Pessoal de Nível Superior - CAPES como "Nacional A", destacando a sua relevância no meio contábil, tanto pelo nível dos trabalhos publicados, tendo inclusive uma seção internacional, como também pela própria qualidade de apresentação do periódico.

É relevante ressaltar a importância da participação de membros estrangeiros no corpo editorial do periódico, fato que demonstra contatos mantidos pelos editores com publicações de outros países e também pela instituição que o produz. Vale salientar que não basta a revista manter uma listagem de membros estrangeiros para garantir a qua- lidade de uma publicação; é necessário que esses profissionais e colaboradores sejam solicitados para atuarem como colaboradores efetivos. A Revista Contabilidade \& Finanças - USP possui $13,33 \%$ de estrangeiros no seu corpo editorial.

\subsection{Análise de Resultados}

O estudo buscou evidenciar os vários aspectos do periódico, tais como: quantidade de artigos e fascículos/ano, número máximo de autores por artigo e fascículo, média de autores por artigo e por fascículo, filiação acadêmica, formação/titulação dos autores, localidade do autor, gênero, nacionalidade, tipologia de estudos, número médio de obras das listas bibliográficas por artigo, macro-temas. $\mathrm{O}$ período analisado por Martins (2002) foi de 1989 até o primeiro quadrimestre de 2001. A presente pesquisa foi realizada compreendendo todo o período $2001-2004$.

Numa análise comparativa entre os dados observados por Martins (2002) e as mudanças ocorridas desde então, constata-se que:

Tabela 1 - Distribuição dos Fascículos e Artigos Caderno de Estudos 1989-2001

\begin{tabular}{|c|c|c|c|}
\hline ANO & $\begin{array}{c}\text { № DE } \\
\text { FAScículos }\end{array}$ & $\begin{array}{c}\text { № DE } \\
\text { ARTIGOS }\end{array}$ & $\begin{array}{l}\text { № MÉDIO DE } \\
\text { ARTIGOS POR } \\
\text { FASCÍCULO }\end{array}$ \\
\hline 1989 & 1 & 4 & 4 \\
\hline 1990 & 1 & 4 & 4 \\
\hline 1991 & 1 & 4 & 4 \\
\hline 1992 & 3 & 12 & 4 \\
\hline 1993 & 3 & 9 & 3 \\
\hline 1994 & 2 & 8 & 4 \\
\hline 1995 & 1 & 4 & 4 \\
\hline 1996 & 2 & 6 & 3 \\
\hline 1997 & 2 & 10 & 5 \\
\hline 1998 & 3 & 19 & 6,3 \\
\hline 1999 & 3 & 13 & 4,3 \\
\hline 2000 & 2 & 8 & 4,0 \\
\hline 2001 & 1 & 5 & 5,0 \\
\hline TOTAL & 25 & 106 & 4,2 \\
\hline
\end{tabular}

Fonte: Martins (2002). 


\section{Tabela 2 - Distribuição dos Fascículos e Artigos Revista Contabilidade \& Finanças - USP 2001-2004}

\begin{tabular}{|c|c|c|c|c|c|}
\hline ANO & № DE FAScícuLOS & № DE ARTIGOS & $\begin{array}{l}\text { № MÉDIO DE } \\
\text { ARTIGOS POR } \\
\text { FASCíCULO }\end{array}$ & $\begin{array}{l}\text { № DE PÁGINAS DE } \\
\text { ARTIGO POR ANO }\end{array}$ & $\begin{array}{c}\text { № MÉDIO DE } \\
\text { PÁGINAS DE } \\
\text { ARTIGO POR ANO }\end{array}$ \\
\hline 2001 & 3 & 17 & 5,7 & 270 & 15,9 \\
\hline 2002 & 3 & 18 & 6,0 & 255 & 14,2 \\
\hline 2003 & 4 & 32 & 8,0 & 440 & 13,7 \\
\hline 2004 & 4 & 31 & 7,7 & 406 & 13,1 \\
\hline TOTAL & 14 & 98 & 7,0 & 1371 & 14,0 \\
\hline
\end{tabular}

Ao longo da existência do periódico, nunca houve interrupção em sua publicação, apesar de ter apresentado certa irregularidade na sua periodicidade: às vezes anual, semestral e quadrimestral. Desde 2001, as edições têm se mantido regulares quadrimestralmente, tendo tido uma edição comemorativa em 2003 e outra em 2004. Quanto à quantidade de artigos por fascículo não havia estabilidade no período 1989-2001, variando entre 2 e 7 com média de 4,2 artigos por fascículo. No entanto, esse número aumentou no período de 2001-2004 passando a ter uma variação de 5 a 8 e média de 7 artigos por fascículo. Desde a edição oㅡ 30 (setembro/dezembro de 2002) têm sido publicados 8 artigos por edição, apenas duas foram editadas com 7, e a partir daí as edições começaram a ter uma Seção Internacional e uma para Comunicações. No período de 1989-2001, era expressiva a variação da quantidade de páginas por artigo - de 5 a 47, com média de 15,4. Em 2001-2004, essa variação diminuiu para 7 a 26 páginas por artigo e média de 14,0 páginas por artigo (ver tabelas 1 e 2).

Tabela 3 - Número Máximo de Autores por Artigo e Fascículo Revista Contabilidade \& Finanças - USP 2001-2004

\begin{tabular}{|c|c|c|c|c|c|}
\hline № de Autores por Artigo & 2001 & 2002 & 2003 & 2004 & TOTAL (2001/2004) \\
\hline Máximo 1 autor & 3 & 12 & 12 & 5 & 32 \\
\hline Máximo 2 autores & 12 & 5 & 14 & 17 & 48 \\
\hline Máximo 3 autores & 1 & 1 & 6 & 6 & 14 \\
\hline Máximo 4 autores & 1 & 0 & 0 & 3 & 4 \\
\hline Total de artigos & 17 & 18 & 32 & 31 & 98 \\
\hline Total de autores/ano & 34 & 25 & 58 & 69 & 186 \\
\hline Média de autores por artigo & 2,00 & 1,39 & 1,81 & 2,23 & 1,90 \\
\hline Total de fascículos/ano & 3 & 3 & 4 & 4 & 14 \\
\hline Média de autores por fascículo & 11,33 & 8,33 & 14,50 & 17,25 & 13,28 \\
\hline
\end{tabular}

Desde o início da publicação da Revista em 1989, o número máximo de autores por artigo não excede a quatro. No período compreendido entre 1989-2001 a maior parte dos artigos, cerca de $77 \%$, foi assinada por um único autor, já entre 2001-2004 a maioria dos artigos, $48 \%$, foi assinada por dois autores, seguida de $32 \%$ por um único autor. A média de autores por artigo, nesse segundo período, é de 1,90 e de autores por fascículo 13,28. 
Tabela 4 - Autores Quanto a Filiação Acadêmica Revista Contabilidade \& Finanças - USP 2001-2004

\begin{tabular}{lcccccc} 
Filiação Acadêmica & $\mathbf{2 0 0 1}$ & $\mathbf{2 0 0 2}$ & $\mathbf{2 0 0 3}$ & $\mathbf{2 0 0 4}$ & TOTAL & TOTAL (\%) \\
Professor/pesquisador - USP & 8 & 9 & 16 & 19 & 52 & 27,96 \\
\hline Alunos de Pós-Graduação - USP & 8 & 4 & 7 & 9 & 28 & 15,05 \\
\hline Alunos de Graduação - USP & 1 & 0 & 0 & 0 & 1 & 0,54 \\
\hline Professores de outras entidades & 5 & 5 & 22 & 30 & 62 & 33,33 \\
\hline Alunos de Pós-Graduação de outras entidades & 1 & 0 & 3 & 2 & 6 & 3,23 \\
\hline Alunos de Graduação de outras entidades & 4 & 0 & 0 & 0 & 4 & 2,15 \\
\hline Universidades estrangeiras & 4 & 3 & 9 & 5 & 21 & 11,29 \\
\hline Sem vínculo acadêmico & 3 & 4 & 1 & 4 & 12 & 6,45 \\
\hline TOTAL & $\mathbf{3 4}$ & $\mathbf{2 5}$ & $\mathbf{5 8}$ & $\mathbf{6 9}$ & $\mathbf{1 8 6}$ & $\mathbf{1 0 0 , 0 0}$ \\
\hline
\end{tabular}

No período avaliado por Martins (2002), 19892001 , constatou-se que aproximadamente $40 \%$ dos autores eram professores do Departamento de Contabilidade e Atuária da FEA-USP, 49,6\% alunos do Programa de Pós-Graduação em Contabilidade e Controladoria e apenas $10,5 \%$ dos autores pertenciam a outras Instituições, ou seja, 89,6\% tinham alguma ligação com a USP. Ao analisar-se o período 2001-2004, percebeu-se uma quebra do processo de endogenia antes observado, quando se constatou a redução desse percentual para $43,55 \%$, e o restante, $56,45 \%$, são de autores de outras entidades, sendo $11,29 \%$ de autores estrangeiros.

\section{Tabela 5 - Formação/Titulação dos Autores \\ Revista Contabilidade \& Finanças - USP 2001-2004}

\begin{tabular}{|c|c|c|c|c|c|c|}
\hline FORMAÇÃO/TITULAÇÃO DOS AUTORES & 2001 & 2002 & 2003 & 2004 & TOTAL & TOTAL (\%) \\
\hline Sem Titulação & - & - & - & 1 & 1 & 0,54 \\
\hline Especialista & - & - & - & 1 & 1 & 0,54 \\
\hline Pós-Doutor & 1 & - & - & - & 1 & 0,54 \\
\hline Professor/ Pesquisador & 2 & - & - & 1 & 3 & 1,61 \\
\hline Phd & - & - & - & 1 & 1 & 0,54 \\
\hline Doutor & 8 & 6 & 24 & 27 & 65 & 34,94 \\
\hline Mestre & 3 & 3 & 4 & 7 & 17 & 9,14 \\
\hline Prof. sem Titulação Identificada & 5 & 10 & 20 & 18 & 53 & 28,49 \\
\hline Bacharel & - & 1 & - & 1 & 2 & 1,08 \\
\hline Graduando & 6 & - & - & - & 6 & 3,23 \\
\hline Doutorando & 5 & 2 & 3 & 7 & 17 & 9,14 \\
\hline Mestrando & 4 & 3 & 7 & 5 & 19 & 10,21 \\
\hline TOTAL & 34 & 25 & 58 & 69 & 186 & 100,00 \\
\hline
\end{tabular}


Tabela 6 - Autores Quanto a Localidade

Revista Contabilidade \& Finanças - USP

2001-2004

\begin{tabular}{|c|c|c|c|c|c|c|}
\hline LOCALIDADE DOS AUTORES & 2001 & 2002 & 2003 & 2004 & TOTAL & TOTAL (\%) \\
\hline SP & 19 & 16 & 26 & 34 & 95 & 51,07 \\
\hline MS & - & - & - & 2 & 2 & 1,08 \\
\hline RJ & 3 & - & 7 & 2 & 12 & 6,45 \\
\hline PB & - & - & - & 1 & 1 & 0,54 \\
\hline SC & 4 & 2 & 7 & 4 & 17 & 9,14 \\
\hline DF & 1 & 2 & - & - & 3 & 1,61 \\
\hline CE & - & 1 & 3 & 7 & 11 & 5,91 \\
\hline PE & - & - & 1 & 3 & 4 & 2,15 \\
\hline ES & 1 & - & 4 & 1 & 6 & 3,23 \\
\hline MG & - & - & - & 1 & 1 & 0,54 \\
\hline BA & 1 & 1 & - & 1 & 3 & 1,61 \\
\hline RS & - & - & 1 & 2 & 3 & 1,61 \\
\hline PR & - & - & - & 1 & 1 & 0,54 \\
\hline $\mathrm{RN}$ & 1 & - & - & 2 & 3 & 1,61 \\
\hline Estrangeiro & 4 & 3 & 9 & 6 & 22 & 11,83 \\
\hline S/Identificação & - & - & - & 2 & 2 & 1,08 \\
\hline TOTAL & 34 & 25 & 58 & 69 & 186 & 100,00 \\
\hline
\end{tabular}

Tabela 7 - Autores Quanto ao Gênero

Revista Contabilidade \& Finanças - USP

2001-2004

\begin{tabular}{lccccc} 
QUANTO AO GÊNERO & FEMININO & MASCULINO & TOTAL & FEMININO (\%) & \multicolumn{2}{c}{ MASCULINO (\%) } \\
2001 & 7 & 27 & 34 & 20,59 & 79,41 \\
\hline 2002 & 5 & 20 & 25 & 20,00 & 80,00 \\
\hline 2003 & 20 & 38 & 58 & 34,48 & 65,52 \\
\hline 2004 & 25 & 44 & 69 & 36,23 & 63,77 \\
\hline TOTAL & $\mathbf{5 7}$ & $\mathbf{1 2 9}$ & $\mathbf{1 8 6}$ & $\mathbf{3 0 , 6 5}$ & $\mathbf{6 9 , 3 5}$ \\
\hline
\end{tabular}

Conforme mostram os dados das tabelas 5 a 7, a maioria dos autores são: doutores - cerca de 34,94\%; localizados em São Paulo - 51,07\%; e do sexo masculino - 69,35\%. Percebeu-se que ainda é pouco incentivada a pesquisa nos cursos de graduação, em que apenas 3,23\% dos artigos foram escritos por graduandos. Ao mesmo tempo, é indubitável a grande colaboração de autores que são mestres, doutores, mestrandos e doutorandos, em torno de $63,43 \%$, ou seja, é um percentual considerável de trabalhos oriundos do stricto sensu. No período 2001-2004, nota-se que grande parte dos autores ainda é de São Paulo, 51,07\%, mas esse percentual teve uma redução considerável, pois, no período compreendido entre 1989-2001, só os autores localizados em São Paulo, que eram ligados a USP, representavam 89,6\%, conforme Martins (2002). Atualmente, há uma maior participação de 
autores estrangeiros e de outras Instituições. Autores do sexo masculino ainda são predominantes, no entanto, o percentual de autoras do sexo feminino tem crescido.

\section{Tabela 8 - Autores Quanto a Nacionalidade \\ Revista Contabilidade \& Finanças - USP 2001-2004}

\begin{tabular}{|c|c|c|c|c|c|c|}
\hline NACIONALIDADE & 2001 & 2002 & 2003 & 2004 & TOTAL & TOTAL (\%) \\
\hline Brasileira & 30 & 22 & 49 & 63 & 164 & 88,17 \\
\hline Portuguesa & 2 & 1 & 4 & 4 & 11 & 5,90 \\
\hline Venezuelana & 0 & 0 & 1 & 0 & 1 & 0,54 \\
\hline Espanhola & 2 & 0 & 3 & 1 & 6 & 3,23 \\
\hline Colombiana & 0 & 1 & 0 & 0 & 1 & 0,54 \\
\hline Argentina & 0 & 1 & 1 & 0 & 2 & 1,08 \\
\hline Polonesa & 0 & 0 & 0 & 1 & 1 & 0,54 \\
\hline TOTAL & 34 & 25 & 58 & 69 & 186 & 100,00 \\
\hline
\end{tabular}

Também é relevante para reforçar a qualidade de um periódico que tenha artigos publicados por autores estrangeiros. A Revista Contabilidade \& Finanças - USP, além de ter seu corpo editorial composto por alguns membros estrangeiros, tem publi-

\section{Tabela 9 - Número Médio de Obras das Listas Bibliográficas por Artigo Caderno de Estudos - 1989-2001}

\begin{tabular}{ll} 
ANO & Número Médio de Obras por Artigo \\
1989 & $1,25\left(^{\star}\right)$ \\
\hline 1990 & 13,8 \\
\hline 1991 & $6,5\left(^{\star \star}\right)$ \\
\hline 1992 & $6,0\left(^{\star \star \star}\right)$ \\
\hline 1993 & $9,9\left(^{\star \star \star *}\right)$ \\
\hline 1994 & $8,6\left(^{\star \star \star \star *}\right)$ \\
\hline 1995 & $14,0\left(^{\star \star \star \star \star \star}\right)$ \\
\hline 1996 & 15,2 \\
\hline 1997 & 15,8 \\
\hline 1998 & 12,8 \\
\hline 1999 & 20,8 \\
\hline 2000 & 19,0 \\
\hline 2001 & 25,8
\end{tabular}

cações de autores internacionais que representam aproximadamente $11,83 \%$ do total de autores, o que é bastante positivo quanto à apresentação da revista em formato adequado às exigências de periódicos com status internacional. $\left(^{\star}\right)$ dos 4 artigos divulgados, apenas um registrou lista bibliográfica.

$\left(^{* \star}\right)$ dos 4 artigos divulgados, apenas dois registraram lista bibliográfica.

$\left(^{\star \star \star}\right)$ dos 12 artigos divulgados, apenas cinco não registraram lista bibliográfica.

$\left(^{(* \star *}\right)$ dos 9 artigos divulgados, apenas quatro não registraram lista bibliográfica.

$\left({ }^{\star \star \star \star \star}\right)$ dos 8 artigos divulgados, apenas três não registraram lista bibliográfica.

$\left(^{* \star * \star * \star}\right)$ dos 4 artigos divulgados, apenas dois não registraram lista bibliográfica.

Fonte: Martins (2002) 


\section{Tabela 10 - Número Médio de Obras das Listas Bibliográficas por Artigo Revista Contabilidade \& Finanças - USP 2001-2004}

\begin{tabular}{lccc} 
ANO & № de Títulos Consultados & № de Artigos & № Médio de Obras por Artigo \\
2001 & 163 & 17 & 9,59 \\
\hline 2002 & 361 & 18 & 20,06 \\
\hline 2003 & 361 & 32 & 11,28 \\
\hline 2004 & 741 & 31 & 23,90 \\
\hline TOTAL & $\mathbf{1 6 2 6}$ & $\mathbf{9 8}$ & $\mathbf{1 6 , 5 9}$ \\
\hline
\end{tabular}

Observação: Todos os artigos publicados de 2001 a 2004 apresentaram lista bibliográfica.

Martins (2002) diz que há uma certa confusão no entendimento dado às referências bibliográficas (material de apoio à construção dos textos) e listas bibliográficas (material consultado para elaboração do artigo) e que muitos artigos que são sínteses de dissertações e teses apresentam pouquíssimas citações referenciadas no texto, e em contrapartida apresentam extensas listas bibliográficas, provavelmente extraídas integralmente do trabalho original; afirma, também, que nos sete primeiros anos de veiculação da revista $42 \%$ não apresentaram referências ou listas bibliográficas. Esse quadro foi alterado visto que, desde 1996, todos os artigos foram editados com referências ou listas bibliográficas. Ao mesmo tempo, não há uma estabilidade no número médio de obras consultadas por artigo em todo período de publicação da revista. Ora essa média sobe, ora desce. Entretanto, observa-se que houve um aumento dessas consultas desde a primeira edição e que 9,35\% das obras consultadas no período 2001-2004 foram de dissertações e teses, sendo a maior parte delas do Departamento de Contabilidade e Atuária da USP. As consultas à Revista Contabilidade \& Finanças - USP foram de $1,78 \%$. Notou-se o reconhecimento da produção acadêmica produzida pelo Departamento de Contabilidade e Atuária da USP e que ainda há baixas taxas de referências à própria revista, conforme já tinha observado Martins (2002).

Tabela 11 - Tipologia de Estudos

Caderno de Estudos 1989 - 2001

\begin{tabular}{lc} 
Abordagens & TOTAL (\%) \\
Exclusivamente bibliográfica & 54,50 \\
\hline Bibliográfica com apoio de exemplos numéricos & 40,50 \\
\hline Empírico-Teórica c/ dados primários e/ou secundários & 5,00 \\
\hline TOTAL & $\mathbf{1 0 0 , 0 0}$
\end{tabular}

Fonte: Martins (2002).

Tabela 12 - Tipologia de Estudos

Revista Contabilidade \& Finanças - USP 2001-2004

\begin{tabular}{|c|c|c|c|c|c|c|}
\hline Abordagens & 2001 & 2002 & 2003 & 2004 & TOTAL & TOTAL (\%) \\
\hline Exclusivamente bibliográfica & 9 & 9 & 10 & 3 & 31 & 31,63 \\
\hline Bibliográfica c/ apoio de exemplos numéricos & 6 & 1 & 7 & 7 & 21 & 21,43 \\
\hline Empírico-Teórica c/ dados primários e/ou secundários & 2 & 8 & 15 & 21 & 46 & 46,94 \\
\hline TOTAL & 17 & 18 & 32 & 31 & 98 & 100,00 \\
\hline
\end{tabular}


Tabela 13 - Tipologia de Estudos

Caderno de Estudos - Comparação

1989-2001/ 2001-2004

\begin{tabular}{|c|c|c|}
\hline Abordagens & TOTAL (\%) 1989-2001 & TOTAL (\%) 2001-2004 \\
\hline Exclusivamente bibliográfica & 54,50 & 31,63 \\
\hline Bibliográfica c/ apoio de exemplos numéricos & 40,50 & 21,43 \\
\hline Empírico-Teórica c/ dados primários e/ou secundários & 5,00 & 46,94 \\
\hline TOTAL & 100,00 & 100,00 \\
\hline
\end{tabular}

Martins (2002) constatou que cerca de $95 \%$ dos artigos publicados no período de sua análise utilizaram a tipologia de pesquisa bibliográfica (explica e discute um tema ou um problema baseando-se em referências teóricas publicadas em revistas, livros, periódicos, jornais, artigos científicos etc.) e apenas $5 \%$ utilizou a pesquisa empírico-teórica (pesquisa bibliográfica e documental com a utilização de técnicas de coleta, identificação, comparação, análise de dados etc.). Diante dos dados observa-se que a abordagem empírico-teórica vem crescendo significativamente, chegando a aproximadamente $46,94 \%$, mesmo tendo ainda um alto percentual de pesquisas bibliográficas.

Tabela 14 - Distribuição Percentual dos Macro-Temas

Caderno de Estudos

1989-2001

\begin{tabular}{lc} 
MACRO-TEMAS & Total (\%) \\
1 - Ajustes de Valores e Correção Monetária & 5,94 \\
\hline 2 - Modelagem Matemática & 6,93 \\
\hline 3 - Sistemas de Informação, Comunicação e Evidenciação & 11,88 \\
\hline 4 - Finanças e Contabilidade & 13,86 \\
\hline 5 - Contabilidade Clássica & 22,77 \\
\hline 6 - Balanço Social e Meio Ambiente & 2,97 \\
\hline 7 - Ensino de Contabilidade e Conhecimento Contábil & 8,91 \\
\hline 8 - GECON - Sistema de Informação de Gestão Econômica & 10,89 \\
\hline 9 - Contabilidade Dirigida a Setores: Rural, Imobiliária, Cooperativas etc. & 3,96 \\
\hline 10 - Legislação e Auditoria & 4,96 \\
\hline 11 - Contabilidade de Custos & 6,93 \\
\hline TOTAL & 100,00 \\
\hline Fonte: Martins (2002).
\end{tabular}




\section{Tabela 15 - Distribuição Percentual dos Macro-Temas}

Revista Contabilidade \& Finanças - USP 2001-2004

\begin{tabular}{lcccccc}
\hline MACRO-TEMAS & $\mathbf{2 0 0 1}$ & $\mathbf{2 0 0 2}$ & $\mathbf{2 0 0 3}$ & $\mathbf{2 0 0 4}$ & Total & Total (\%) \\
\hline - Ajustes de Valores e Correção Monetária & 0 & 0 & 1 & 0 & 1 & 1,02 \\
\hline 2 - Modelagem Matemática & 1 & 0 & 1 & 0 & 2 & 2,04 \\
\hline 3 - Sistemas de Informação, Comunicação e Evidenciação & 6 & 2 & 5 & 4 & 17 & 17,35 \\
\hline 4 - Finanças e Contabilidade & 6 & 6 & 15 & 12 & 39 & 39,80 \\
\hline 5 - Contabilidade Clássica & 0 & 2 & 4 & 2 & 8 & 8,16 \\
\hline 6 - Balanço Social e Meio Ambiente & 0 & 0 & 0 & 1 & 1 & 3,06 \\
\hline 7 - Ensino de Contabilidade e Conhecimento Contábil & 3 & 2 & 3 & 2 & 10 & 10,20 \\
\hline 8 - GECON - Sistema de Informação de Gestão Econômica & 0 & 1 & 2 & 0 & 3 & 3,06 \\
\hline 9 - Contabilidade Dirigida a Setores: Rural, Imobiliária, Cooperativas etc. & - & - & - & - & 0 & 0,00 \\
\hline 10 - Legislação e Auditoria & 0 & 1 & 1 & 4 & 6 & 6,12 \\
\hline 11 - Contabilidade de Custos & 0 & 4 & 0 & 5 & 9 & 9,19 \\
\hline TOTAL & $\mathbf{1 7}$ & $\mathbf{1 8}$ & $\mathbf{3 2}$ & $\mathbf{3 1}$ & $\mathbf{9 8}$ & $\mathbf{1 0 0 , 0 0}$ \\
\hline
\end{tabular}

Tabela 16 - Distribuição Percentual dos Macro-Temas: Comparativo

Caderno de Estudos 1989-2001 e Revista Contabilidade \& Finanças - USP 2001-2004

\begin{tabular}{|c|c|c|}
\hline MACRO-TEMAS & TOTAL (\%) (1989/2001) & TOTAL (\%) (2001/2004) \\
\hline 1 - Ajustes de Valores e Correção Monetária & 5,94 & 1,02 \\
\hline 2 - Modelagem Matemática & 6,93 & 2,04 \\
\hline 3 - Sistemas de Informação, Comunicação e Evidenciação & 11,88 & 17,35 \\
\hline 4 - Finanças e Contabilidade & 13,86 & 39,80 \\
\hline 5 - Contabilidade Clássica & 22,77 & 8,16 \\
\hline 6 - Balanço Social e Meio Ambiente & 2,97 & 3,06 \\
\hline 7 - Ensino de Contabilidade e Conhecimento Contábil & 8,91 & 10,2 \\
\hline 8 - GECON - Sistema de Informação de Gestão Econômica & 10,89 & 3,06 \\
\hline 9 - Contabilidade Dirigida a Setores: Rural, Imobiliária, Cooperativas etc. & 3,96 & 0,00 \\
\hline 10 - Legislação e Auditoria & 4,96 & 6,12 \\
\hline 11 - Contabilidade de Custos & 6,93 & 9,19 \\
\hline TOTAL & 100,00 & 100,00 \\
\hline
\end{tabular}

Foram lidos e analisados todos os artigos do período 2001-2004 a fim de distribuí-los em macrotemas. Inicialmente, utilizaram-se os macro-temas de acordo com Martins (2002), com a finalidade de fazer-se uma comparação entre os períodos 19892001 e 2001-2004. Numa análise posterior, os temas foram distribuídos em macro-temas conforme modelo apresentado por Oliveira (2002), a fim de dar maior ênfase a alguns temas não destacados na pesquisa de Martins (2002). Percebeu-se uma mudança de pesquisas da área de Contabilidade clássica para área de Finanças e Contabilidade. É importante salientar que Martins considerou como Contabilidade Clássica temas ligados à Contabili- 
dade Societária e alguns tratados como Finanças e Contabilidade estão relacionados com a Contabilidade Gerencial e de Mercado, o que evidencia o interesse dos autores em retratar a importância das informações gerenciais como auxiliares no pro- cesso decisório das organizações e, também, sua preocupação com as exigências do mercado que, diante de um contexto cada vez mais competitivo, necessita de trabalhos que auxiliem numa melhor compreensão das relações organizacionais.

Tabela 17 - Distribuição Percentual dos Macro-Temas

Revista Contabilidade \& Finanças - USP - 2001-2004

\begin{tabular}{|c|c|c|c|c|c|c|}
\hline MACRO-TEMAS & 2001 & 2002 & 2003 & 2004 & TOTAL & TOTAL (\%) \\
\hline 1 - Contabilidade e Mercado de Capital & - & 1 & 2 & - & 3 & 3,06 \\
\hline 2 - Educação e Pesquisa Contábil & 2 & 2 & 2 & 2 & 8 & 8,16 \\
\hline 3 - Contabilidade para Empresas em Tipos Específicos de Atividades & - & - & 1 & - & 1 & 1,02 \\
\hline 4 - Contabilidade para Empresas em Tipos Específicos de Organizações & - & - & - & 2 & 2 & 2,04 \\
\hline 5 - História da Contabilidade & 1 & 1 & - & 1 & 3 & 3,06 \\
\hline 6 - Teoria da Contabilidade & - & 2 & 6 & 1 & 9 & 9,20 \\
\hline 7 - Auditoria Externa e Interna & - & 1 & 2 & 3 & 6 & 6,12 \\
\hline 8 - Contabilidade de Custos & - & 2 & - & 2 & 4 & 4,08 \\
\hline 9 - Contabilidade Financeira & 2 & - & 2 & 2 & 6 & 6,12 \\
\hline 10 - Perícia Contábil & - & - & - & - & - & - \\
\hline 11 - Contabilidade Internacional & 3 & - & 3 & - & 6 & 6,12 \\
\hline 12 - Contabilidade Gerencial & 8 & 7 & 12 & 15 & 42 & 42,86 \\
\hline 13 - Exercício Profissional & - & - & - & - & - & - \\
\hline 14 - Contabilidade Pública, Orçamento Público e Finanças Públicas & - & - & 2 & 1 & 3 & 3,06 \\
\hline 15 - Contabilidade Social e Ambiental & 1 & 1 & - & 2 & 4 & 4,08 \\
\hline 16 - Contabilidade Tributária & - & 1 & - & - & 1 & 1,02 \\
\hline TOTAL & 17 & 18 & 32 & 31 & 98 & 100,00 \\
\hline
\end{tabular}

Fonte: Oliveira (2002).

Os temas com maior ocorrência de artigos têm sido: Contabilidade Gerencial, Teoria da Contabilidade, Educação e Pesquisa Contábil, Auditoria Externa e Interna, Contabilidade Financeira e Contabilidade Internacional. Destaca-se a Contabilidade Gerencial com $42,86 \%$ dos artigos publicados. Segundo Maher apud Oliveira (2002), nos periódicos estrangeiros a mudança de pesquisas de áreas puramente financeiras para outras áreas, principalmente gerencial, teve início nos anos 80. No Brasil, essa modificação só veio a ocorrer a partir da década de 90 . Diante da classificação proposta por Oliveira (2002), observa-se a importância das informações produzidas pela Contabilidade Gerencial como auxiliares da gestão; também percebese a preocupação dos acadêmicos e profissionais da Contabilidade em discutir temas relacionados ao co- nhecimento da Teoria da Contabilidade, no intuito de se posicionarem, criticamente, sobre assuntos correlatos ao campo das Ciências Contábeis.

\section{CONSIDERACÕES FINAIS E CONCLUSÕES}

De acordo com a análise comparativa realizada, evidenciou-se que com relação aos fascículos da Revista eles passaram a ter uma periodicidade estável. Quanto aos artigos, observou-se um aumento no número de publicações por fascículo; as publicações que, em grande parte eram feitas por apenas um autor, passaram a ser com dois autores. Os autores, que eram em sua maioria ligados ao Departamento de Contabilidade e Atuária da FEA-USP, agora apa- 
recem em significativo percentual ligados a outras instituições de diversas partes do país e do exterior. A quantidade de autores mais expressiva continua sendo a de Doutores. São Paulo é o Estado com maior número de autores, apesar de ter havido uma redução nesse número e conseqüente aumento da participação de outros Estados e de outros países, principalmente Portugal e Espanha. A quantidade de obras consultadas para a elaboração dos artigos tem crescido ano a ano e a pesquisa a teses e dissertações do Departamento de Contabilidade e Atuária da FEA-USP continua grande. Quanto à tipologia de pesquisa, verificou-se que os autores têm seguido a tendência internacional de publicação de trabalhos com pesquisas empírico-teóricas, fato que demonstra uma mudança considerável quanto à tipologia utilizada, antes predominantemente bibliográfica.

Outro aspecto observado foi a publicação de um número representativo de artigos ligados à Contabilidade Gerencial, demonstrando uma mudança

no foco de preocupação dos autores, em que, num momento de competição acirrada de mercado, as informações gerenciais são de extrema importância para a tomada de decisões.

Conclui-se, então, que a Revista Contabilidade \& Finanças-USP evoluiu consideravelmente desde o período pesquisado por Martins (1989/2001) até o período analisado no presente estudo (2001/2004), observando-se que muitas mudanças ocorridas são decorrentes de sugestões feitas por Martins no trabalho divulgado em 2002.

Por fim, sugere-se um maior rigor científico quanto à elaboração dos resumos publicados nos artigos, para que contenham os objetivos, a metodologia utilizada e as conclusões da pesquisa. Sugere-se, também, um maior incentivo para produção de artigos por graduandos em conjunto com seus professores, a fim de que o estímulo à produção científica comece desde a graduação e não apenas nos cursos de especialização.

\section{REFERÊNCIAS BIBLIOGRÁFICAS}

BEUREN, Ilse Maria. (Org.). Como elaborar trabalhos monográficos em contabilidade: Teoria e prática. São Paulo: Atlas, 2003.

DEMO, Pedro. Metodologia do conhecimento científico. São Paulo: Atlas, 2000.

KRZYZANOWSKI, R.; FERREIRA, M. C. G..Avaliação de periódicos científicos e técnicos brasileiros. Ciência da Informação. Brasília: v. 27, n. 2 , p. $165-175,1998$.

LAKATOS, Eva Maria; MARCONI, Marina de Andrade. Fundamentos de metodologia científica. 4. ed. São Paulo: Atlas, 2001.

LOPES, Jorge. Apostila metodologia da pesquisa aplicada às ciências contábeis. Recife: UFPE, 2004.

MARTINS, Gilberto de Andrade. Manual para elaboração de monografias e dissertações. São Paulo: Atlas, 2000.

Considerações sobre os doze anos do Caderno de Estudos. Revista Contabilidade \& Finanças - USP. São Paulo, $n$. 30, p. 81-88, setembro/dezembro 2002.

NETO, Otávio Ribeiro e Mendonça et al. Estudos sobre as publicações científicas em contabilidade: uma análise de 1990 até 2003. Disponível em: http://www.anpad.org.br/enampad/2004ccg-1854.pdf. Acesso em 10 de abril de 2005.

\section{NOTA:}

Endereço dos autores:

Mestrado Multiinstitucional e Inter-Reginal

Faculdade de Estudos Sociais Aplicados, s/no - Asa Norte

Brasília - DF

70910-900
OLIVEIRA, Marcelle Colares. Análise dos periódicos brasileiros de contabilidade. Revista Contabilidade \& Finanças - USP. São Paulo, n. 29, p. 68-86, maio/ago. 2002.

ORTEGA, Cristina. FÁVERO, Osmar. GARCIA, Walter. Análise dos periódicos brasileiros de educação. Revista Brasileira de Estudos Pedagógicos. Brasília, v. 79, n. 183, p. 161-168, set./dez. 1999.

PUERARI, Dely B. M., PEREIRA, Ma. Nazaré F.. Avaliação dos periódicos científicos nacionais na área da Economia. Ciência e Cultura - Resumos SBPC, São Paulo, v. 43, n. 7 (supl.), p. 547-8, jul. 1991.

SCHWARTZMAN, Simon. A política brasileira de publicações científicas e técnicas: reflexões. Revista Brasileira de Tecnologia. 15 (3): p. 25-32, maio/jun., 1984.

SILVA, Antonio Carlos Ribeiro da. Metodologia da pesquisa aplicada à contabilidade: orientações de estudos, projetos, relatórios, monografias, dissertações, teses. São Paulo: Atlas, 2003.

Maurício Correia et al. Procedimentos metodológicos para a elaboração de projetos de pesquisa relacionados a dissertações de mestrado em ciências contábeis. Revista Contabilidade \& Finanças - USP. São Paulo, n. 36, p. 97-104, setembro/dezembro, 2004.
Universidade Federal de Pernambuco

Av. dos Economistas, $\mathrm{s} / \mathrm{n}^{\circ}$ - Cidade Universitária

Recife - PE

50670-420 